\title{
APPUHN-RADTKE, Sibylle, Visuelle Medien im Dienst der Gesellschaft Jesu. Johann Christoph Storer (1620-1671) als Maler der Katholischen Reform
}

\section{Christophe Duhamelle}

\section{OpenEdition}

\section{Journals}

Édition électronique

URL : http://journals.openedition.org/ifha/1264

DOI : 10.4000/ifha.1264

ISSN : 2198-8943

Éditeur

IFRA - Institut franco-allemand (sciences historiques et sociales)

Référence électronique

Christophe Duhamelle, «APPUHN-RADTKE, Sibylle, Visuelle Medien im Dienst der Gesellschaft Jesu. Johann Christoph Storer (1620-1671) als Maler der Katholischen Reform », Revue de I'IFHA [En ligne], Date de recension, mis en ligne le 01 janvier 2001, consulté le 22 septembre 2020. URL : http:// journals.openedition.org/ifha/1264 ; DOI : https://doi.org/10.4000/ifha.1264

Ce document a été généré automatiquement le 22 septembre 2020.

(CIFHA 


\title{
APPUHN-RADTKE, Sibylle, Visuelle Medien im Dienst der Gesellschaft Jesu. Johann Christoph Storer (1620-1671) als Maler der Katholischen Reform
}

\author{
Christophe Duhamelle
}

1 Cet ouvrage (issu d'une habilitation en histoire de l'art) a pour premier mérite, en établissant un catalogue très soigneux de son œuvre, de tirer de l'ombre un peintre qui, en son temps, a connu une renommée certaine, s'est assuré une aisance matérielle croissante, et a participé au plus haut niveau à l'administration et aux affaires politiques de sa ville, Constance. Issu d'une famille de peintres, Storer a reçu une éducation soignée - sans doute chez les jésuites - et un apprentissage approfondi dans l'atelier de son père, puis à Augsbourg et aux Pays-Bas (dont le style qui s'épanouit alors et auquel Rubens sert d'emblème exerce par la suite une influence croissante sur sa manière) mais il ne peut, dans le contexte déprimé de la guerre de Trente Ans, demeurer en Allemagne. De 1639/40 à 1655, c'est donc à Milan qu'il s'installe, élargissant ses horizons et recevant des commandes très diversifiées. Le retour à Constance, alors que la reconstruction assure à nouveau du travail, se traduit par une orientation quasi exclusive vers les sujets religieux. En effet, l'activité de Storer s'exerce principalement au sein d'un réseau jésuite qui, indépendamment même de l'identité des mécènes, assure la cohésion des programmes iconographiques, des types de commandes et des artistes sollicités. La peinture sur toile (surtout la peinture d'autel), le frontispice et la gravure pédagogique représentent donc désormais l'essentiel de l'œuvre de Storer.

2 C'est ce lien étroit entre l'artiste et les besoins spécifiques ainsi que le programme de pédagogie religieuse de la société de Jésus qui constitue sans doute l'apport majeur, pour les historiens, du travail de S.A.-R. Non que le thème, par lui-même, soit terra incognita ; et l'auteur de résumer fort clairement, d'emblée, toute la réflexion sur l'image qui mène de Bellarmin, Richeôme et Possevino jusqu'à Otonelli, en passant par 
les jésuites germaniques Jacob Gretser (De sancta cruce, 1598/99) et Matthäus Rader (Bavaria sancta, 1615-1628), entre autres. Mais S.A.-R. parvient sur cet exemple précis (d'autant plus précieux que la peinture allemande du XVIIe s. reste peu étudiée) à établir de manière très concrète la façon dont les réseaux de commanditaires et les thèmes iconographiques entretiennent d'étroites relations. L'insistance sur l'Immaculée Conception de la Vierge Marie, sur saint Joseph, ou bien sûr sur la geste triomphante des fondateurs jésuites récemment canonisés, est ici précisément analysée, datée, et développée dans tous ses aspects didactiques et symboliques.

3 L'auteur aurait peut-être pu aller plus loin en élargissant sa bibliographie aux Volkskundler, qui ont produit sur l'iconographie jésuite des travaux essentiels (Edgar Harvolk, ou encore Eduard Frieß et Gustav Gugitz dans l'Österreichische Zeitschrift für Volkskunde de 1958 ainsi qu'Elfriede Grabner dans la même revue en 1992, pour ne citer que quelques exemples). Il n'en reste pas moins que ce travail sur Johann Christoph Storer, bien documenté et remarquablement illustré, n'apporte pas seulement des connaissances nouvelles sur un peintre prospère, notable actif de sa cité, mais aussi sur un "dévot " (au sens où l'entend Louis Châtellier), membre de la congrégation mariale de Constance depuis 1659 , qui met son art et son style au service d'une action jésuite que cet ouvrage nous permet de connaître un peu mieux. 